\title{
Technical Status Report on the Prediction of Amorphous Phase Separation in Multicomponent Borosilicate Glasses
}

by

D. K. Peeler

Westinghouse Savannah River Company

Savannah River Site

Aiken, South Carolina 29808

\section{DOE Contract No. DE-AC09-96SR18500}

This paper was prepared in connection with work done under the above contract number with the U.S. Department of Energy. By acceptance of this paper, the publisher and/or recipient acknowledges the U.S. Government's right to retain a nonexclusive, royalty-free license in and to any copyright covering this paper, along with the right to reproduce and to authorize others to reproduce all or part of the copyrighted paper. 


\section{DISCLAmERR}

Portions of this docoment may be illegible in electronic image products. Imsges are produced from the best arailable original docoment 


\section{DISCLAIMER}

This report was prepared as an account of work sponsored by an agency of the United States Government. Neither the United States Government nor any agency thereof, nor any of their employees, makes any warranty, express or implied, or assumes any legal liability or responsibility for the accuracy, completeness, or usefulness of any information, apparatus, product, or process disclosed, or represents that its use would not infringe privately owned rights. Reference herein to any specific commercial product, process, or service by trade name, trademark, manufacturer, or otherwise does not necessarily constitute or imply its endorsement, recommendation, or favoring by the United States Government or any agency thereof. The views and opinions of authors expressed herein do not necessarily state or reflect those of the United States Government or any agency thereof.

This report has been reproduced directly from the best available copy.

Available to DOE and DOE contractors from the Office of Scientific and Technical Information, P. O. Box 62, Oak Ridge, TN 37831; prices available from (423) 576-8401.

Available to the public from the National Technical Information Service, U. S. Department of Commerce, 5285 Port Royal Road, Springfield, VA 22161. 
WSRC-TR-97-00313

Revision 0

\author{
TECHNICAL STATUS REPORT ON THE \\ PREDICTION OF AMORPHOUS PHASE SEPARATION \\ IN MULTICOMPONENT BOROSILICATE GLASSES (U)
}

\title{
Objective
}

The objective of the Tank Focus Area Optimize Waste Loading task is to enhance the definition of the acceptable processing window for high-level waste vitrification plants by reducing the uncertainty of various compositional/property models through specific data development. With a reduction in model uncertainty, limitations on current acceptance constraints may be reduced allowing for increased waste loadings and larger processing or operational windows. Enhanced composition/property model predictions coupled with an increased waste loading will decrease the processing time and waste glass disposal costs (i.e., overall lifecycle costs). This should also lead to a better definition of the acceptable processing window for Hanford and DWPF to develop strategies for treating different HLW types (sequencing and blending). Two such compositional/property models currently being evaluated by the Tanks Focus Area are related to the development of amorphous phase separation and the prediction of liquidus temperature in multicomponent borosilicate glasses.

This status report describes the current status for predicting of amorphous phase separation in multicomponent borosilicate glasses with reference to the two major development criteria (composition and thermal history). The goal of this subtask is to perform targeted research activities to define and, where applicable, extend the boundaries of existing phase stability models that restrict HLW glass waste loading. Specifically, the focus will be on delimiting boundaries for immiscible phase separation. The development of data, understanding, and quantitative description for composition and kinetic effects on the development of amorphous phase separation will continue in FY98. This effort will provide insight into the compositional effects on phase stability and will lead to a better understanding of the methods used to predict the development of amorphous phase separation in HLW glasses. 


\section{Background}

Amorphous phase separation is defined as the separation, upon cooling, of a homogeneous melt into two or more liquid phases (e.g., glass-in-glass phase separation). Borosilicate glasses are prone to amorphous phase separation. Two domains, differing in composition, typically develop when an alkali borosilicate undergoes glass-in-glass phase separation. One domain is silica-rich while the other is an alkali-boron enriched phase. Multicomponent borosilicate glasses tend to partition in a similar manner.

Tomozawa [1] recognized three microstructural types depending upon whether the kinetics of separation are governed by nucleation/growth or spinodal decomposition mechanisms. The three microstructural types are:

Type A: $\quad$ Both phases are highly interconnected and continuous structures.

(spinodal decomposition)

Type B: $\quad$ The more durable phase is dispersed as discrete droplets in a continuous matrix of the less durable phase.

(nucleation/growth)

Type C: $\quad$ The less durable phase exists as discrete droplets in a continuous matrix of the more durable phase.

(nucleation/growth)

Depending upon the developed microstructure, phase separation can profoundly affect glass properties, in particular, durability towards aqueous dissolution. The rate controlling factor in the dissolution process is primarily defined in terms of the durability of the continuous matrix phase. Chemical durability usually deteriorates upon the development of a Type A or Type B microstructure because the less durable (alkali-boron enriched) phase is continuous in both cases. The development of a Type $\mathrm{C}$ microstructure usually has little effect on durability, but has been shown to improve the durability in some cases.[2,3]

The transition in compositional space between homogeneous borosilicate glasses and those characterized by a phase separated microstructure may be delineated by a sharp change in durability. For glasses within or near the immiscibility dome, a poor response to a standard chemical durability test (such as the Product Consistency Test) may be a good indicator for the potential of amorphous phase separation. ${ }^{\dagger \dagger}$ A deterioration in durability for a phase separated glass is the primary concern for nuclear waste glasses which is heightened by the fact that most metal oxides and fission products tend to partition into the more soluble phase.[4] A deterioration in product performance may occur over an extremely narrow compositional range.

It A poor response to a standard durability test could be attributed to several factors including the presence of amorphous phase separation, effects of crystallization, or the lack of a 3-D glass structure. The durability response can be used as an indicator for phase separation but detailed microstructural analysis of the glass is required to determine if phase separation has developed. In fact, if the position of the immiscibility dome is generally known then the durability response could be used for further definition assuming a Type A or B microstructure develops. 
Equally important to the effect of amorphous phase separation on the glass durability is the predictability of immiscibility within multicomponent systems. In binary systems, determination of miscibility boundaries is fairly straight forward and has been well documented. However, as the systems become progressively more complex (i.e., binary to ternary to multicomponent), detail mapping of immiscibility domes requires an extensive study involving the preparation and evaluation of numerous glasses. Therefore, it would be advantageous to model the immiscibility domes of multicomponent systems based on the knowledge of simpler systems and single-component effects of modifying cations in ternary systems.

Several attempts have been made to empirically or theoretically predict immiscibility behavior within multicomponent systems. Kawamoto and Tomozawa [5] have proposed a "simple and reliable" method to estimate the miscibility boundaries in ternary silicate systems. Although this method has been successfully in predicting immiscibility in several ternary silicate systems, it has not been applied to the multicomponent systems typical of nuclear waste vitrification. Other techniques have been developed to predict or estimate the immiscibility boundaries but were limited to binary and a few select ternary systems and again were not applied to multicomponent borosilicate systems. [6-9]

Taylor [4] developed a model to predict immiscibility in multicomponent systems. This model was based on simpler systems and single component effects in ternary systems. Taylor's rule are based on the position of a $\mathrm{Na}_{2} \mathrm{O}-\mathrm{B}_{2} \mathrm{O}_{3}-\mathrm{SiO}_{2}(\mathrm{NBS})$ submixture system from the multicomponent system with respect to the immiscibility dome. If the NBS submixture lies outside the projected immiscibility dome, Taylor predicts that additions of various oxides will not promote phase separation in multicomponent systems. If the NBS submixture lies within the dome, additions of oxides with highly polarizing cations will induce phase separation. Peeler et. al. [10] and Peeler and Hrma [11] have applied this approach to high-level (simulated) radioactive waste glasses.

Another model developed at the Savannah River Technology Center (currently being utilized by DWPF) is based on the development of amorphous phase separation in quaternary systems. ${ }^{*}$ Good discrimination between homogeneous and phase separated glasses was achieved when applied to simulated high-level waste glasses.

One possible means of further defining the line of demarcation for phase separation would be based on a durability response. However, that alone is insufficient due to the strong relationship between glass composition and durability. Other analytical techniques are required to confirm the presence or absence of a phase separated microstructure. Methods typically used include optical microscopy, scanning electron microscopy (SEM) and transmission electron microscopy (TEM). ${ }^{*}$ The particular method of choice is dependent upon the scale of separation and sometimes requires an acid-etch to enhance the phase separation contrast.

\footnotetext{
* A detailed description of this model is not given due to a pending patent. [Jantzen 1995]

* More sophisticated, sensitive techniques can also be used such as Small Angle X-ray Scattering (SAXS), Nuclear Magnetic Resonance (NMR), and/or Small Angle Neutron Scattering (SANS) depending upon the scale of separation. The scale of separation is highly dependent upon the thermal history (i.e., kinetically driven).
} 
The development of amorphous phase separation is both thermodynamically and kinetically driven. That is, its development is not only a function of composition but also is highly dependent upon kinetics factors, of which thermal history is of primary importance. Sufficient heat treatment may be necessary for kinetic development of amorphous phase separation even if the glass composition is favorable for its development. Thermal history not only determines the formation probability but also has a strong influence on the scale to which the microstructure develops. The extent or degree of phase separation in high-level glasses can therefore only be controlled if the thermal history is controlled. To avoid phase separation in a uncontrolled cooling rate process one is limited to control over composition. High-level waste glasses are formulated outside the immiscibility dome to thermodynamically avoid the development of amorphous phase separation.

In order to avoid the immiscibility dome, the location of the compositional transition region (whether sharp or diffuse) must be known. If the position of the immiscibility dome is well understood, glasses can be formulated close to the immiscibility dome without risking the development of amorphous phase separation. This detailed understanding and the ability to predict the development of amorphous phase separation could translate into a larger compositional window from which the particular vitrification process is based. Many existing predictive models (based on composition/property relationships) have large uncertainties and their application may lead to a reduction in waste loading and/or the available processing window in terms of compositional space. The existing databases although limited support this conservative approach. The present situation calls for expanding the databases and developing a tool to optimize waste loading and/or increase the compositional processing window, thereby minimizing production and disposal costs.

\section{Experimental}

Per the statement of work defined by Pacific Northwest National Laboratory (PNNL), MPO No. 293847-A-M6, the Savannah River Technology Center (SRTC) analyzed a limited number of existing simulated high-level waste glasses for the presence of amorphous phase separation. The glasses were selected based on current DWPF model predictions of phase separation coupled with their response to aqueous dissolution (PCT). Glasses simulating the current DWPF "sludge-only" flowsheet as well as other potential DWPF flowsheets were evaluated. This selection agrees with the task as defined in Subtask A of TTP \# SR1-6-WT-31 and outlined in the PNNL scope of work for MPO No. 293847-AM6.

Transmission electron microscopy (TEM) was used to evaluate both "as-fabricated" and "acid etched" glasses. Samples investigated were melted at $1150^{\circ} \mathrm{C}$ for 4 hours and then "air cooled" after pouring onto a stainless steel plate after 4 hours at $1150^{\circ} \mathrm{C}$. Samples were evaluated on as "as-fabricated" or "etched" basis. Acid etching is a common method used to enhance the phase separation contrast.** Etched samples were placed in $0.1 \% \mathrm{HF}$ or $0.1 \% \mathrm{HCl}$ for time periods of 30

\footnotetext{
** Texture within a microstructure is sometimes masked by similar density differences between the two phases that enhances the detection of amorphous phase separation via electron microscopy techniques. Also, the scale of separation can prohibit an accurate classification unless etching is used to provide surface relief.
} 
seconds to 1 minute. When analyzing etched samples, caution was used to avoid the misclassification of amorphous phase separation for artifacts remaining on the sample as a result of the etching process. Secondary phases enriched in $\mathrm{F}$ and/or $\mathrm{Cl}$ are often detected as a result of the etching process.

\section{Sample Selection}

DWPF is currently operating a Batch 1 "sludge-only" flowsheet that blends Tank 51 sludge with Frit $200 .^{\dagger}$ A compositional variation study for the Batch 1 flowsheet was performed in which glasses were formulated ranging from 20 - 30 wt\% sludge (in $1 \mathrm{wt} \%$ increments) along the projected Process Acceptable Region (PRAR) as defined by current models. In the study, a relatively constant durability (based on normalized boron release) was measured for glasses with Frit 200 contents between 70 and $76 \mathrm{wt} \%$ (see Figure 1). However, a general trend in the data suggest that the durability gradually decreases at higher frit contents $(\geq 76 \mathrm{wt} \%$ Frit 200). It should be noted that the measured B release rates for glasses within the PRAR (as well as those outside the PRAR at higher waste loadings) were well below the Environmental Assessment (EA) glass limits.

Use of the current DWPF phase separation discriminator predicts (based on as analyzed compositions) three WP200 glasses to be phase separated: WP200-4; WP200-14; and WP200-16. ${ }^{\dagger}$ These are three of the 6 glasses near the frit-rich end member that show higher than $0.1 \mathrm{~g} / \mathrm{L}(\log [\mathrm{B}])$ release in Figure 1. The development of amorphous phase separation may explain the decreased durability of those glasses. Two WP200 glasses were chosen for evaluation: WP200-4 and WP200-5. Although WP200-5 was not predicted to be phase separated (based on "as analyzed" compositions), WP200-5 had the lowest durability of all WP200 glasses evaluated and is near the frit-rich end-member. Therefore, the glass may be phase separated although not predicted due to analytical error.

\footnotetext{
$\dagger$ The "sludge-only" flowsheet does not include precipitate hydrolysis aqueous (PHA) additions; only Tank 51 sludge and Frit 200.

${ }^{\dagger}$ WP200-15 was not predicted to be phase separated based on the analyzed chemical composition although its composition was similar to WP200-14 and WP200-16 and also showed a fairly high $B$ release.
} 


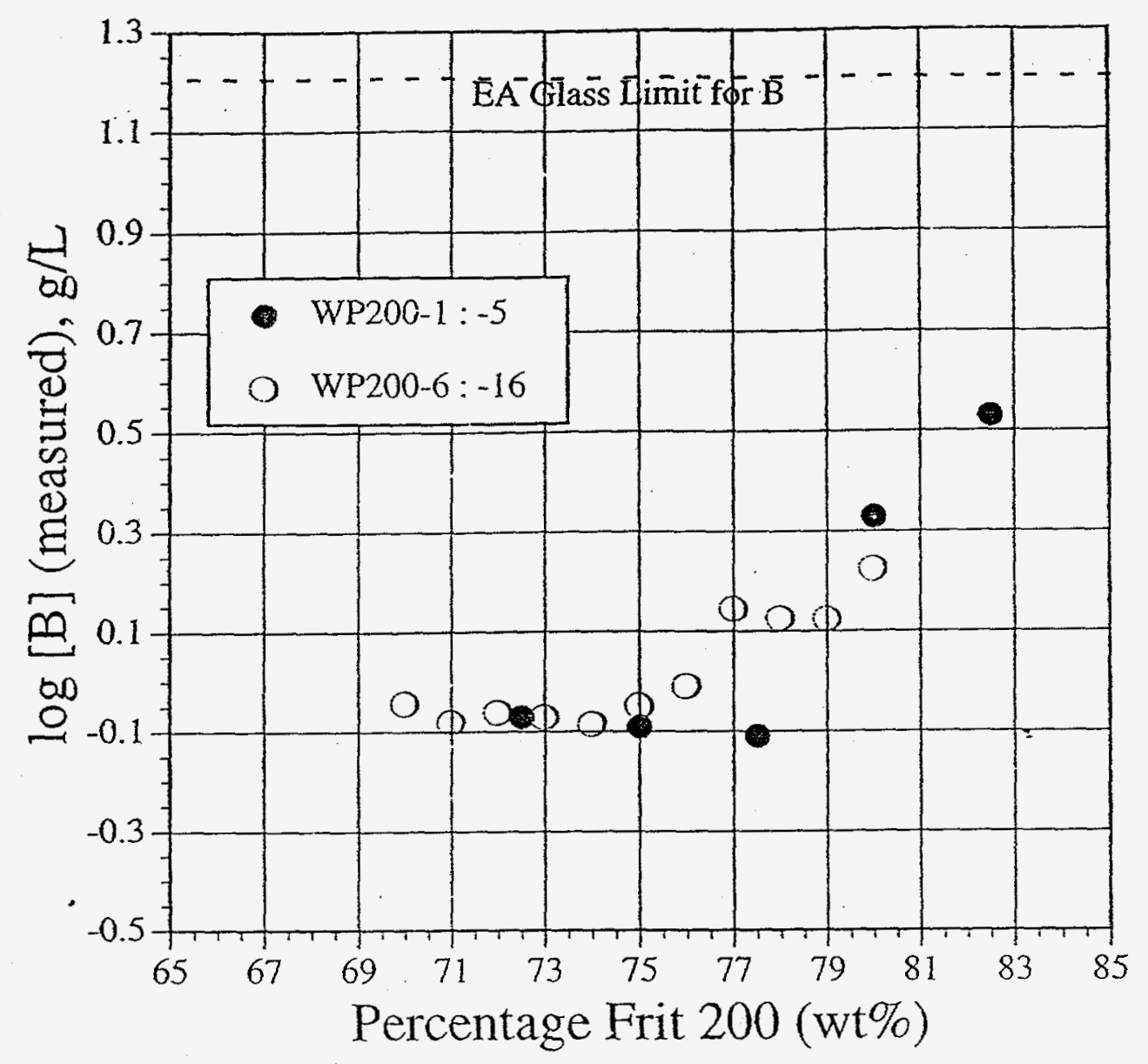

Figure 1. Percentage of Frit 200 Content Versus log [B] for "Sludge-Only" WP200 Glasses. 
A second flowsheet (the "coupled flowsheet") of interest to DWPF utilizes Tank 51 sludge, Frit 202, and PHA. A compositional variation study has been performed to evaluate the expected processing window for this flowsheet as well. Figure 2 graphically shows the log normalized boron release plotted against weight percent Frit 202 (at constant PHA content) for some WP202 glasses. For each series of constant PHA curves, there appears to be a "break point" in the durability. That is, the measured log boron release remains relatively constant at lower frit loadings but increases quite dramatically at the "break point". This break point may be associated with the formation of amorphous phase separation. The highest frit containing glasses for the $17.5 \%, 12.5 \%$, and $2.5 \%$ PHA curves are WP202-4, WP202-8. and WP202-16, respectively. The current discriminator predicts (based on analyzed chemical compositions) that WP202-4 and WP202-8 are phase

separated which could be the basis for the "sudden reduction" in durability. ${ }^{\text {t+ }}$ Frit 202 is known to be phase separated (see Figure 3 - nucleation/growth

microstructure). Therefore, as the WP202 glasses become more frit-rich, one may expect that the glasses would have a greater potential to be phase separated. The current discriminator model also predicts WP202-3, $-4,-8,-12,-22$, and -23 to be phase separated. For this report WP202-4 and WP202-9 (predicted to be homogeneous) were selected for evaluation.

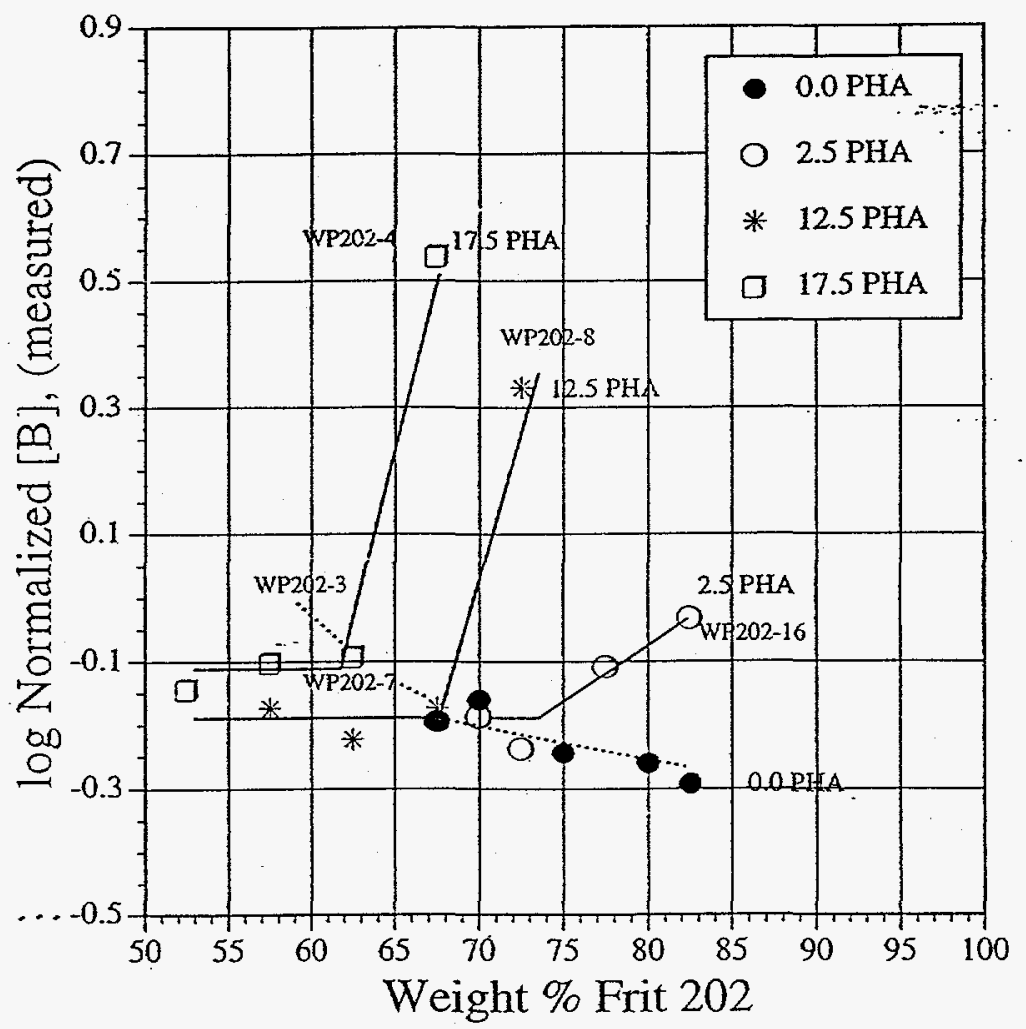

Figure 2. Weight \% Frit Versus log [B] at Constant PHA for Various WP202 Glasses.

tt广 WP202-16 is not predicted to be phase separated based on the analyzed compositions but was the only glass analyzed exceeding the quality control window of $100 \pm 5 \%$ on an oxide basis. 

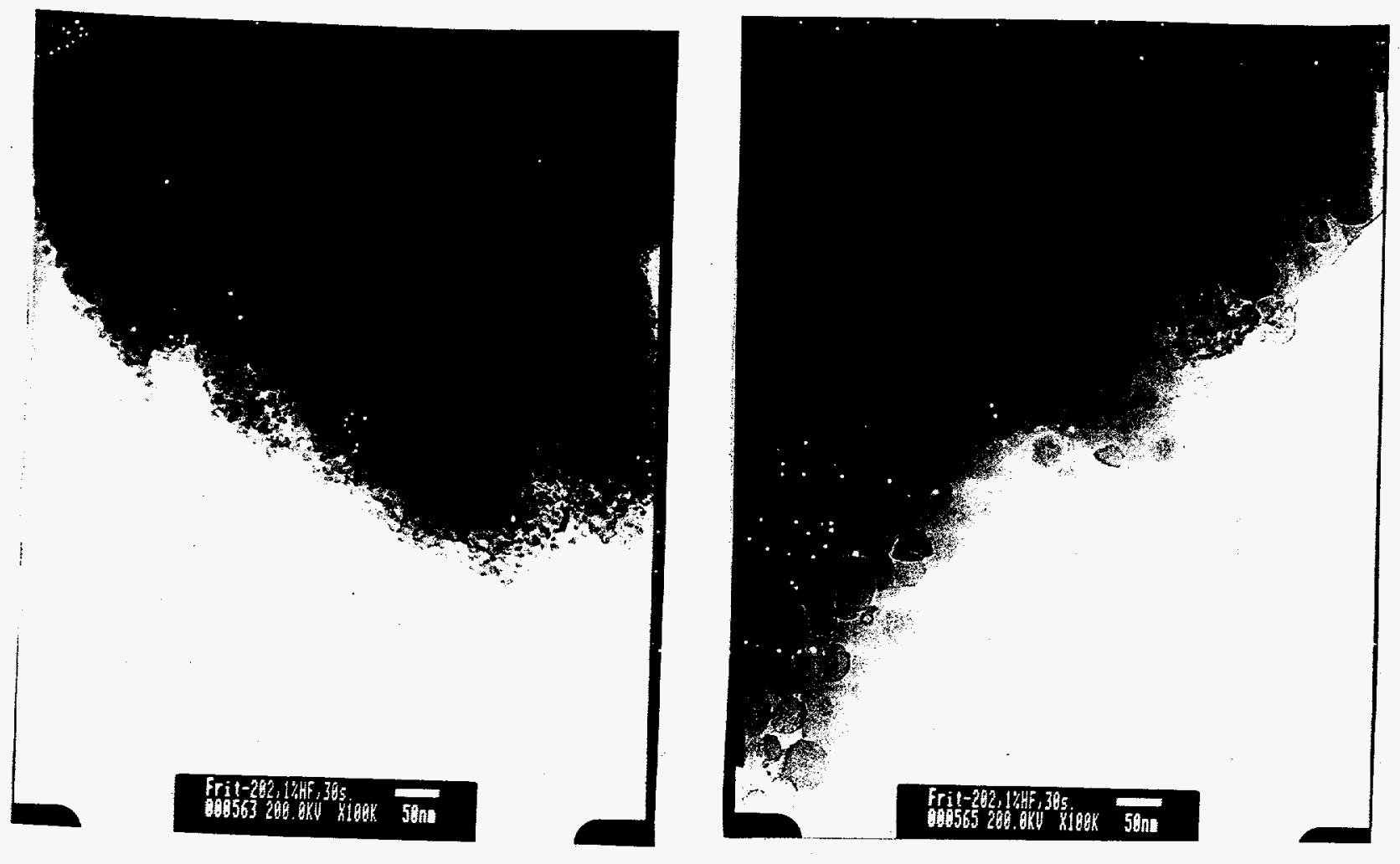

Figure 3. TEM Micrograph of Frit 202.

Table I lists the simulated HLW glasses evaluated in this study. Acid etching was utilized to enhance phase separation contrast for certain samples. Also listed in Table I are two simulated HLW glasses (2-29 and 2-31) known to be phase separated. $[10,11]$ The thermal history of these two glasses is vastly different than all other listed in Table I. These glasses were subjected to a heat treatment corresponding to the calculated cool down schedule of the centerline within a HLW canister. SRTC model predictions (based on chemical analysis) for the presence of amorphous phase separation are also given. "Homogeneous" classification indicates that the model predict no amorphous phase separation. 
Table I. List of Simulated HLW Glasses Evaluated.

\begin{tabular}{ll}
\hline \hline Glass & $\begin{array}{l}\text { Model } \\
\text { Prediction }\end{array}$ \\
\hline WP200-4 & Phase Separated \\
WP200-5 & Homogeneous \\
WP202-4 & Phase Separated \\
WP202-9 & Homogeneous \\
WP202-15 & Homogeneous \\
Frit 202 & Phase Separated \\
$2-29$ & Phase Separated \\
$2-31$ & Homogeneous \\
${ }^{\dagger}$ Model predictions based on the current DWPF \\
\multicolumn{2}{c}{ phase separation discriminator. }
\end{tabular}

\section{Results and Discussion}

\section{WP200 Glasses}

WP200-4 was predicted to be phase separated (see Table I) and is less durable than most counterpart WP200 glasses (see Figure 1). In fact, only one glass (WP200-5) had a poorer durability as measured by boron release from the standard PCT test. Figures 4 and 5 show the TEM analysis of the "as-fabricated" WP200-4. Both TEM micrographs appear homogeneous with little indication of amorphous phase separation. However, when WP200-4 is acid etched (see Figure 6), a mottled texture is present in the glass structure (this structure is extremely difficult to detect due to its scale). For comparison purposes, Figures 7 and 8 show TEM micrographs of Glass 2-29 and Glass 2-31. Glass 2-29 shows a classic example of a phase separated microstructure developed by the nucleation/growth mechanismamorphous spheres isolated in a continuous matrix of a second composition. Both phases appear to be highly interconnected in the microstructure of Glass 2-31 which is related to spinodal decomposition. It should be noted that the current discriminator predicts 2-29 and 2-31 to be phase separated and homogeneous respectively. The misclassification of 2-31 could be the result of slight compositional errors or the heat treatment effects. The enhanced scale of separation observed in Figures 7 and 8 could be related to the thermal history of these two glasses since these glasses were subjected to a calculated centerline canister cooling schedule. This heat treatment schedule would kinetically favor the development of amorphous phase separation relative to the "as fabricated" (or air quenched) WP200 glasses. The results for the presence of amorphous phase separation in WP200-4 are inconclusive. However, based on the texture and the durability response it appears that the glass is phase separated but the scale of separation is extremely small. Further analysis on WP200-4 needs to be performed, including the effects of heat treatment or the use of more sensitive analytical techniques to confirm the presence of amorphous phase separation. 


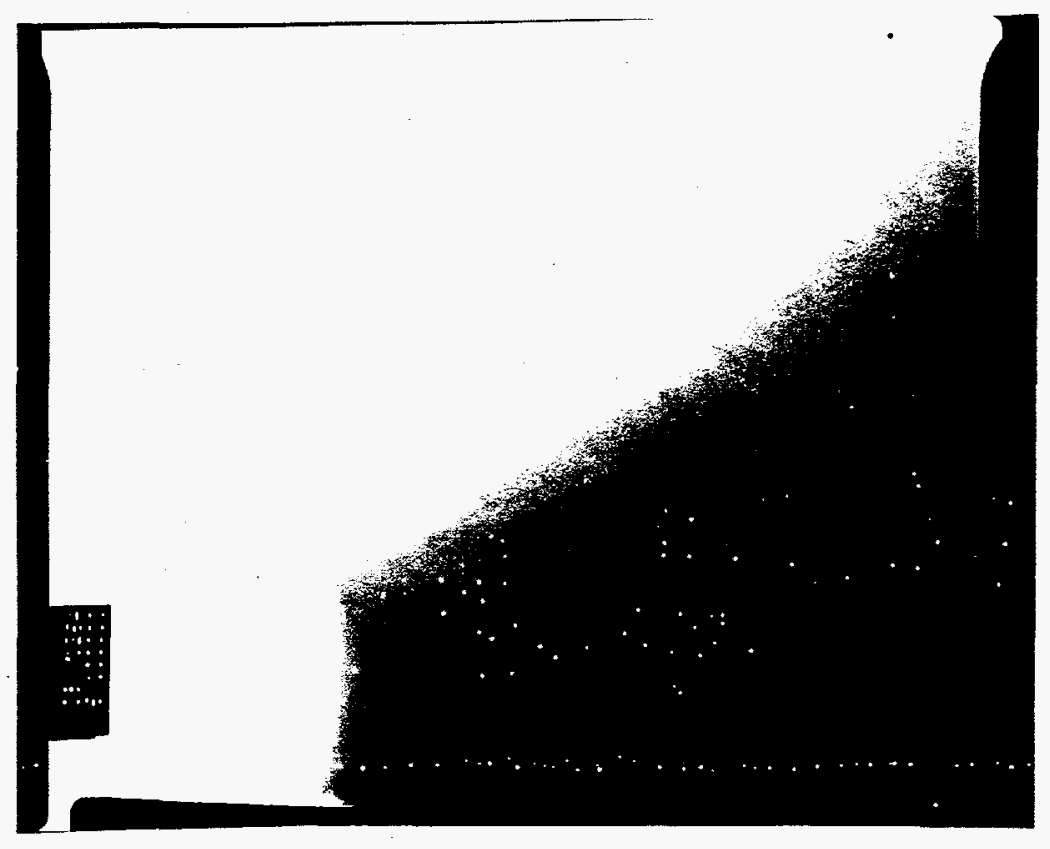

Figure 4. TEM Micrograph of WP200-4 ("as-fabricated"). (magnification $\times 100 \mathrm{~K}$ )

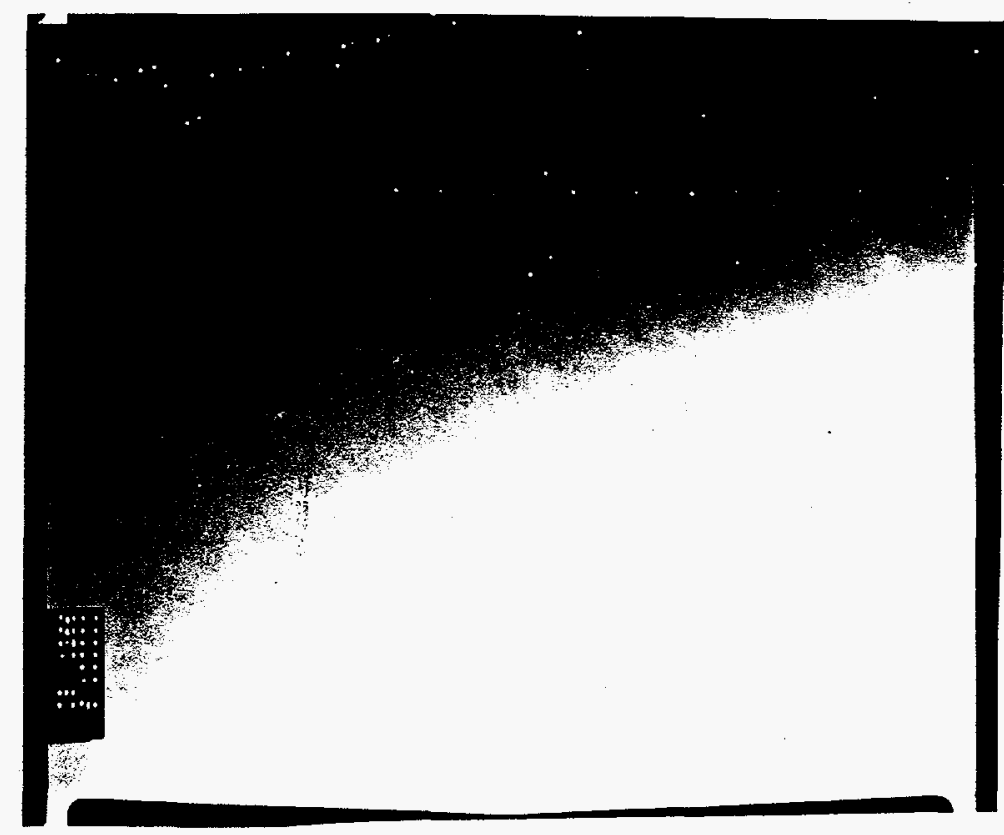

Figure 5. TEM Micrograph of WP200-4 ("as-fabricated"). (magnification $\mathrm{x} 100 \mathrm{~K}$ ) 


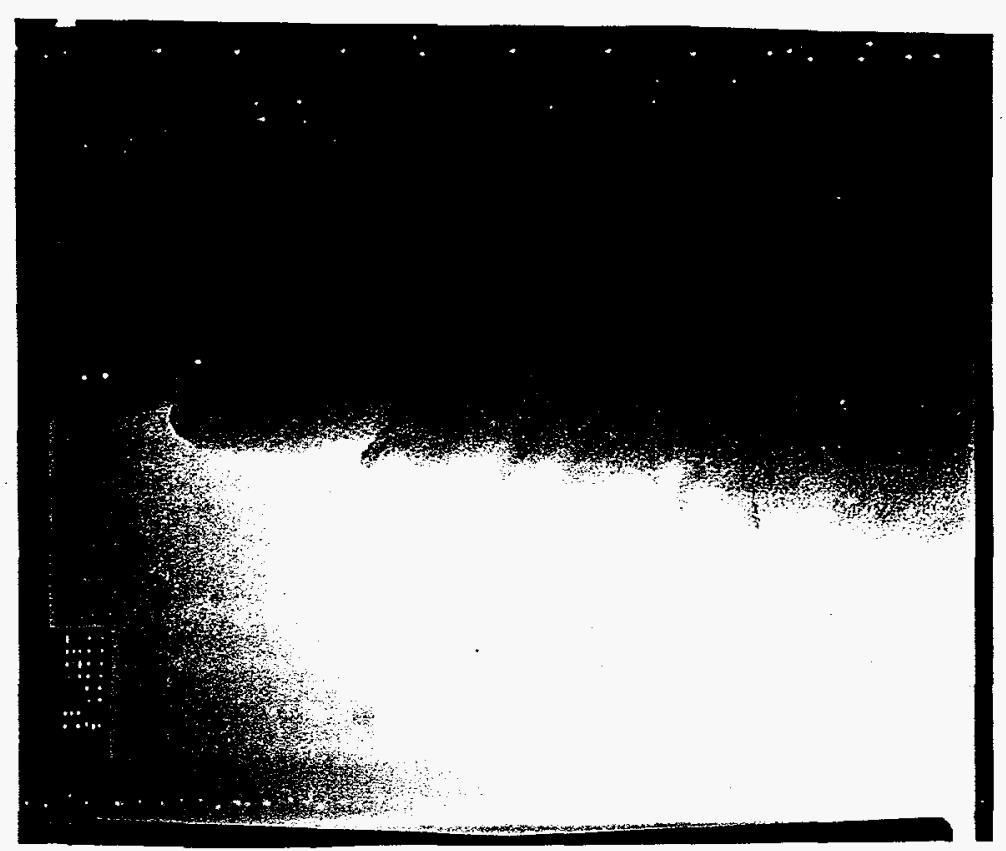

Figure 6. TEM Micrograph of WP200-4 ("acid-etched"). (magnification $\times 100 \mathrm{~K}$ )

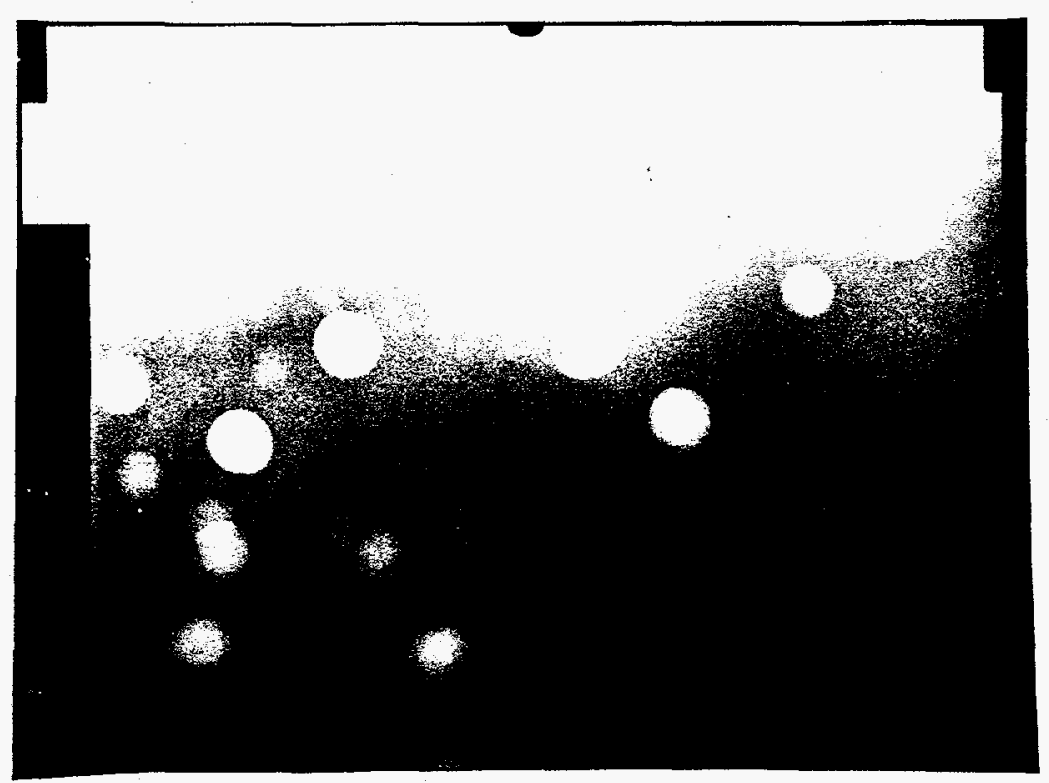

Figure 7. TEM Micrograph of Glass 2-29. (magnification 40,000x) 


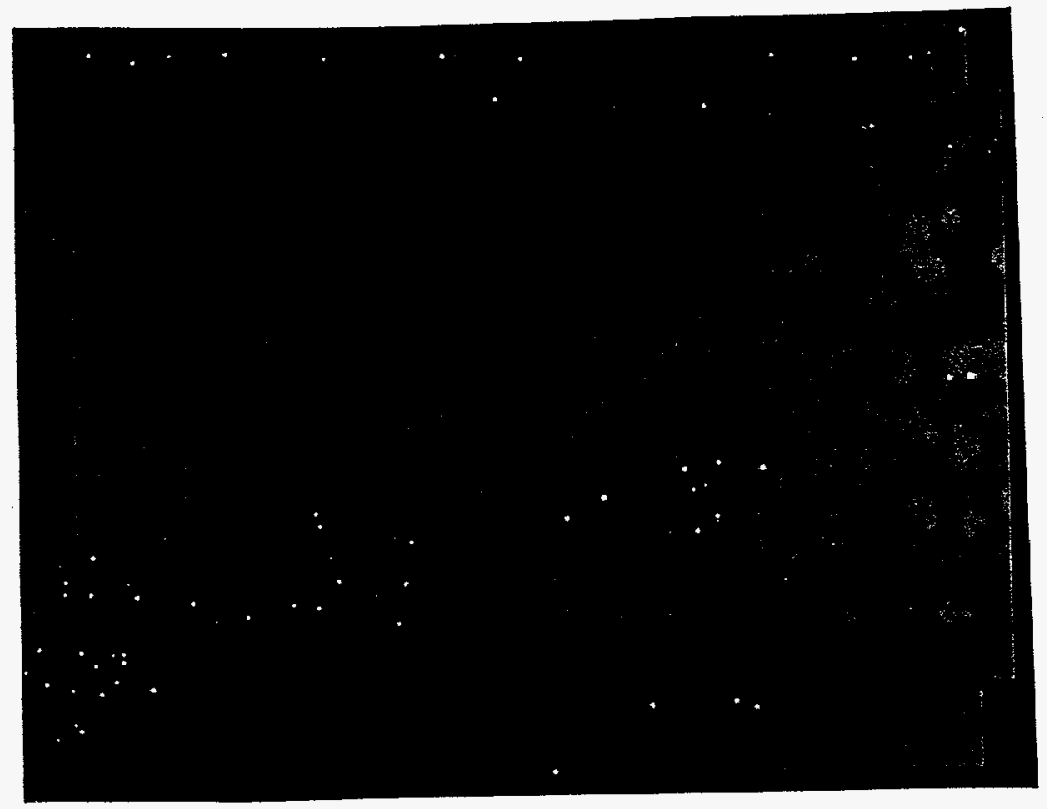

Figure 8. TEM Micrograph of Glass 2-31. (magnification 40,000x)

WP200-5 was the other "sludge-only" flowsheet glass evaluated. This glass had the lowest durability of all the WP200 glasses (Figure 1). As the WP200 glasses become compositionally more frit enriched the durability seems to decrease. However, this glass was predicted to be homogeneous by the current phase separation discriminator based on the chemical analysis. Figures 9 and 10 show TEM micrographs of the "as fabricated" WP200-5 glass. A definite texture is observed in the quenched glasses. Although amorphous phase separation was not confirmed through energy dispersive or more sophisticated analytical techniques such as energy electron loss spectra (EELS), it is highly probable that amorphous phase separation exist. Etched samples were not evaluated due to time constraints. It is possible that the homogeneous prediction by the current model was related to an inaccurate chemical analysis. These slight discrepancies suggest that the immiscibility dome is in close proximity to predicted values. Therefore, a more detail understanding of the development of amorphous phase separation could lead to model enhancement translating to an extension of the operational window. 


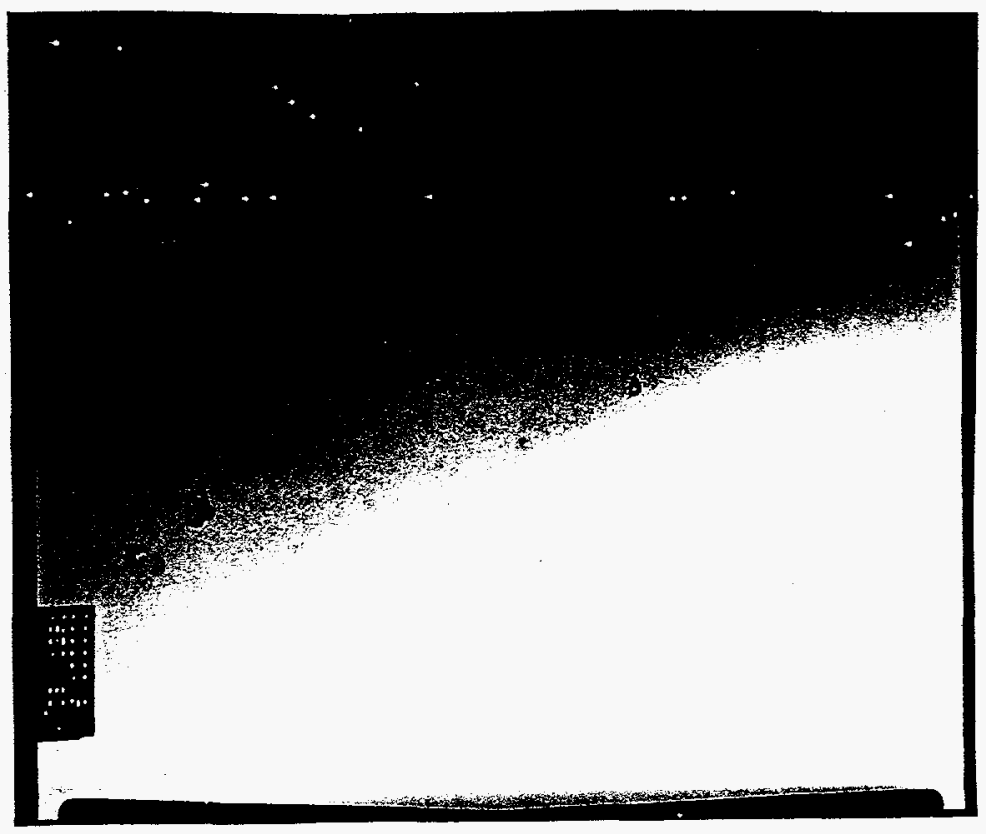

Figure 9. TEM Micrograph of WP200-5 "As-fabricated".

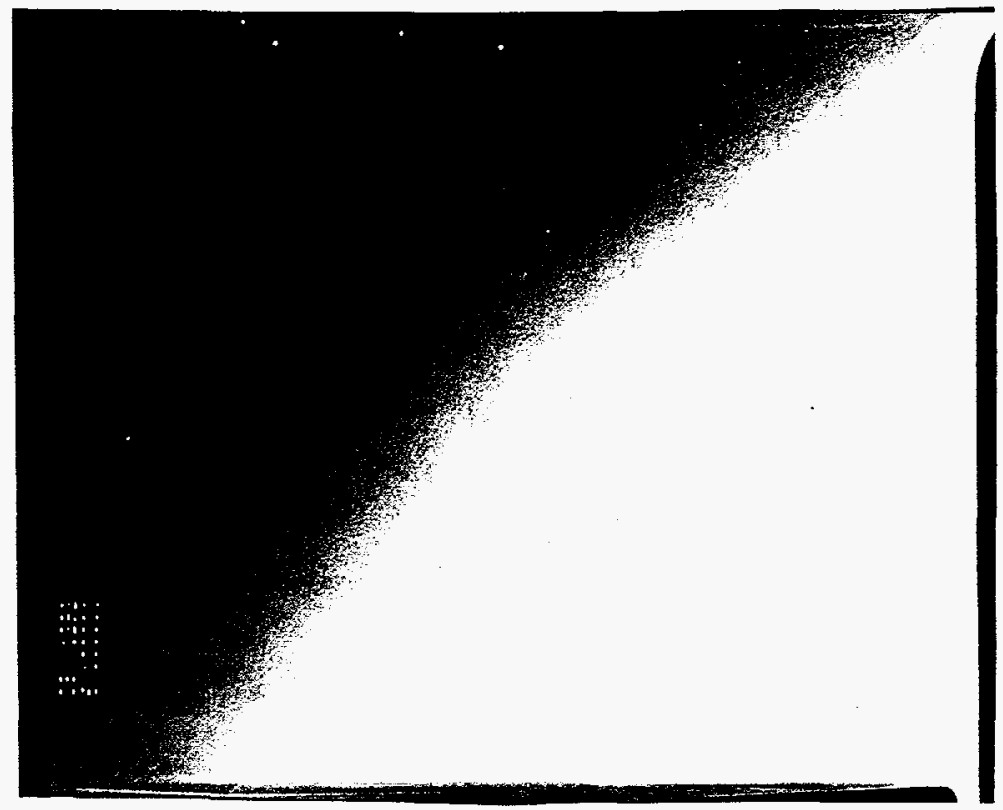

Figure 10. TEM Micrograph of WP200-5 "As-fabricated". 


\section{WP202 Glasses}

Three WP202 glasses were evaluated: WP202-4, WP202-9, and WP202-15. Oniy one of these three glasses (WP202-4) was predicted to be phase separated by the current discriminator. Again, using the durability response as an indicator of the potential for phase separation, WP202-4 is the only glass of these three that shows a dramatic increase in boron release for similar PHA levels (refer to Figure 2). A mottled texture is observed in the "as fabricated" WP202-4 samples (Figures 11 and 12). Again, the scale of separation is extremely small as a result of the thermal history (e.g., quenched glass).

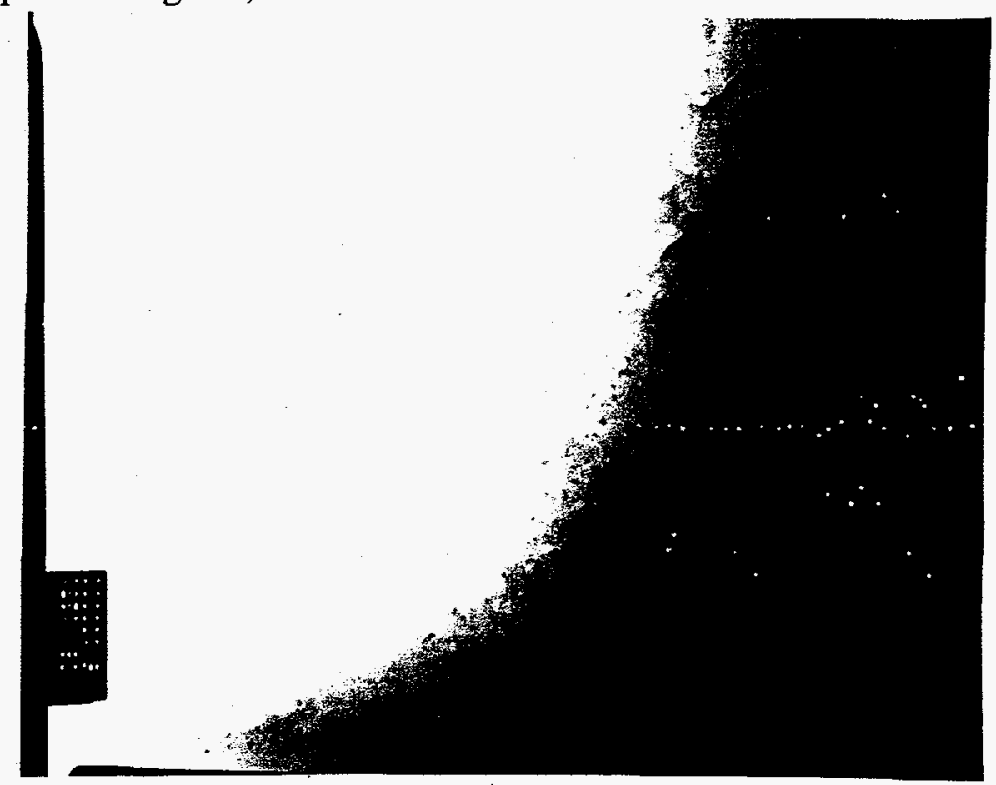

Figure 11. TEM Micrograph of the "As-Fabricated" WP202-4. (x100K)

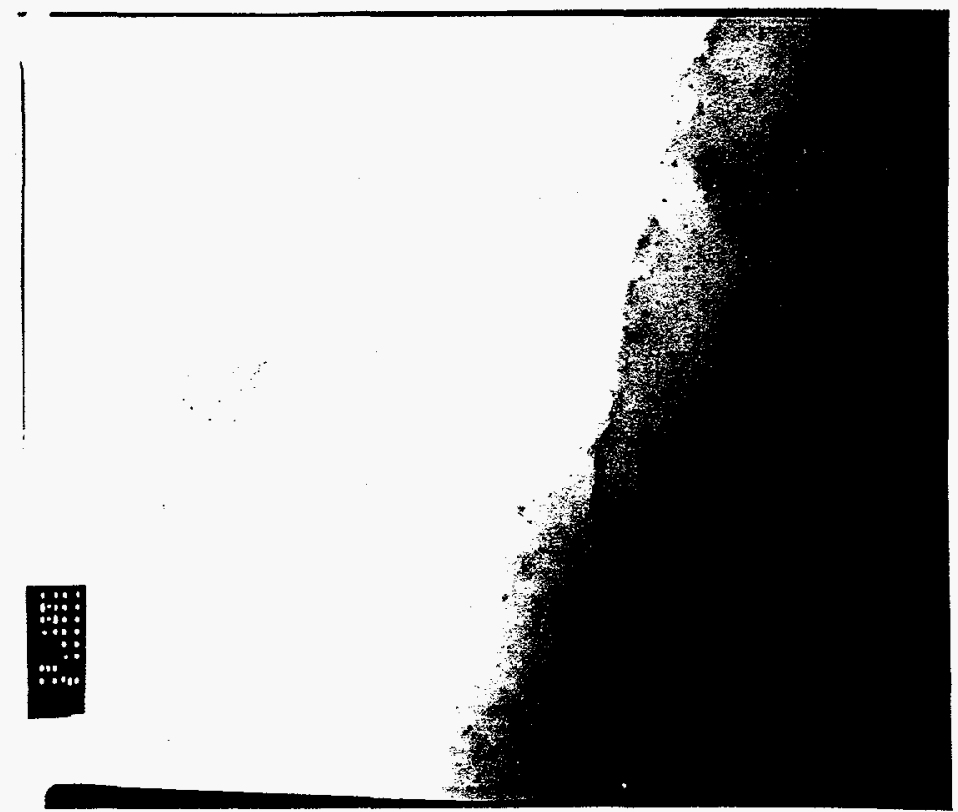

Figure 12. TEM Micrograph of the "As-Fabricated" WP202-4. (x100K) 
Figures 13 and 14 show TEM micrographs of the "as fabricated" WP202-9 sample. The unetched samples appear to be homogeneous which corresponds well to model predictions. Upon etching (Figure 15), it appears that the sample remains homogeneous (no enhancement of phase separation) although artifacts are present of the glass surface due to the etching process. These artifacts are clearly shown on the surface of the etched sample.

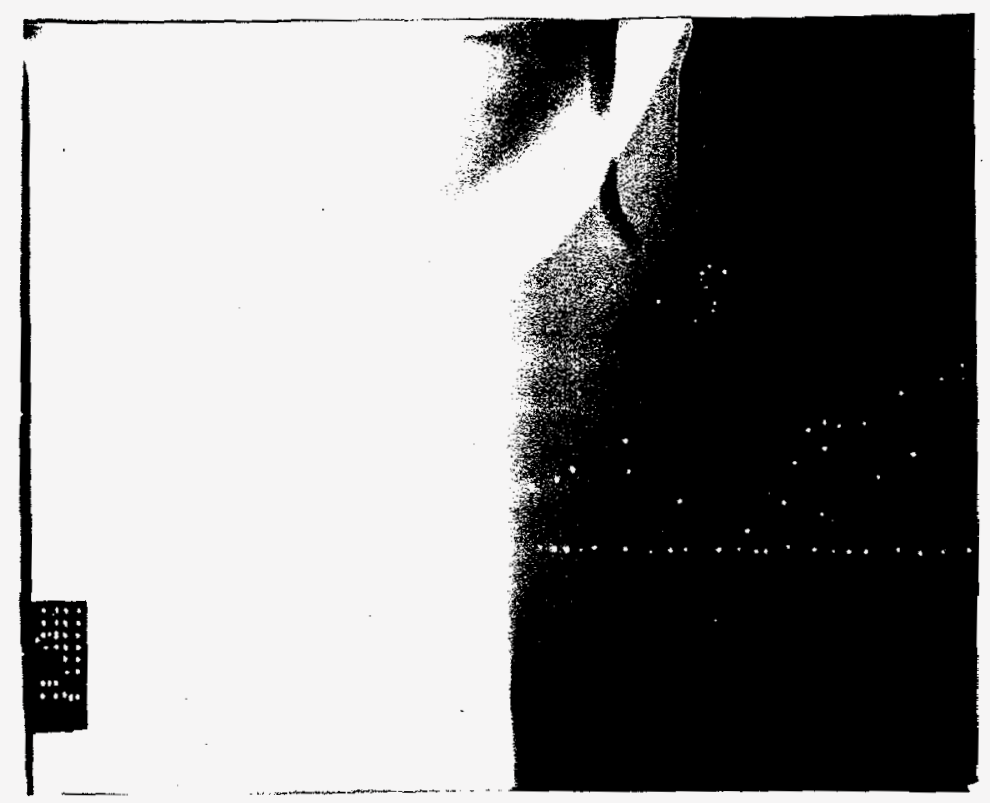

Figure 13. TEM Micrograph of the "As-Fabricated" WP202-9. (x100K)

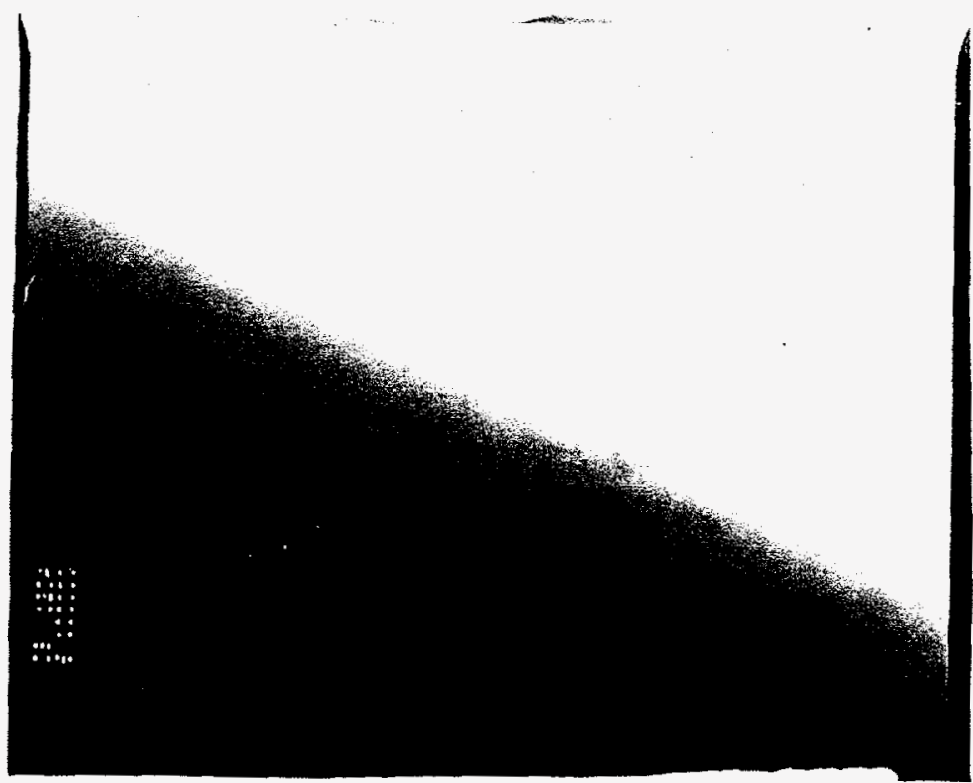

Figure 14. TEM Micrograph of the "As-Fabricated" WP202-9. (x100K) 


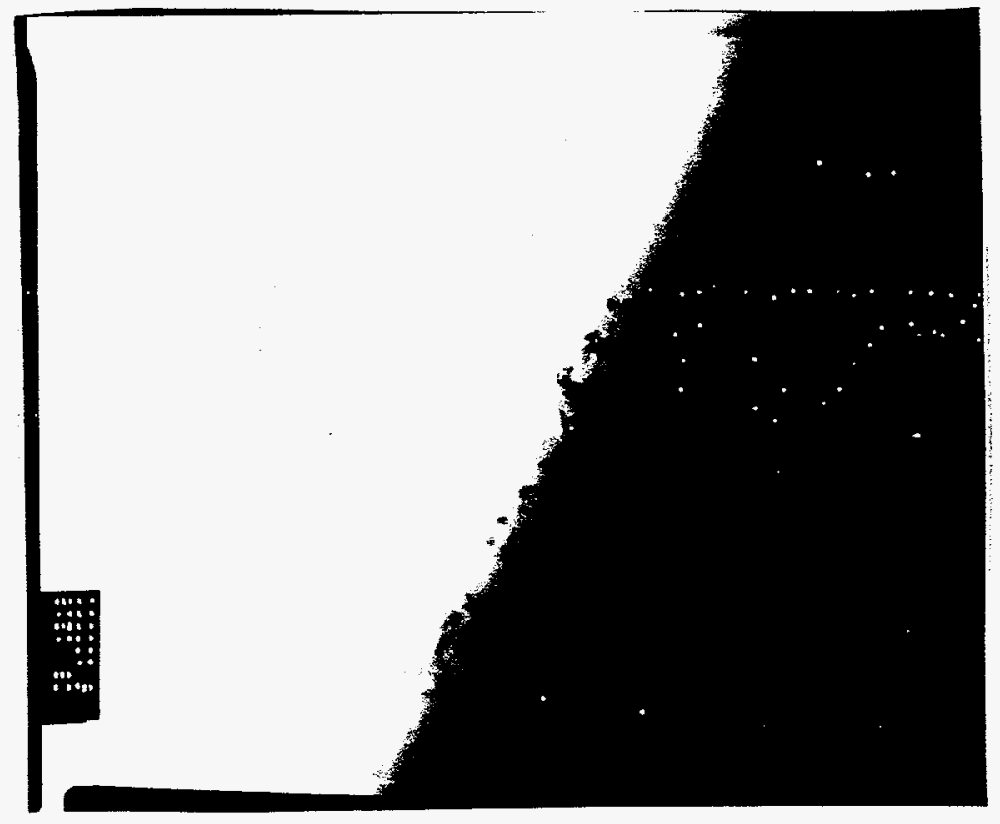

Figure 15. TEM Micrograph of the "Etched" WP202-9. (x100K) 
WP202-15 was the last simulated HLW glass evaluated in this study. The current model predicts this glass to be homogeneous based on the chemical analysis. Projections of the immiscibility dome location suggest that this glass is a "borderline" glass in terms of compositionally favoring phase separation. Based on both "as-fabricated" and etched samples (Figures 16 and 17, respectively), there appears to be a mottled texture in the glass microstructure. If amorphous phase separation is present, the scale of separation is extremely small. Although model predictions do not suggest that phase separation exists, further investigation should evaluate the effects of kinetics (e.g., thermal heat treatment) on the development of phase separation within this glass.

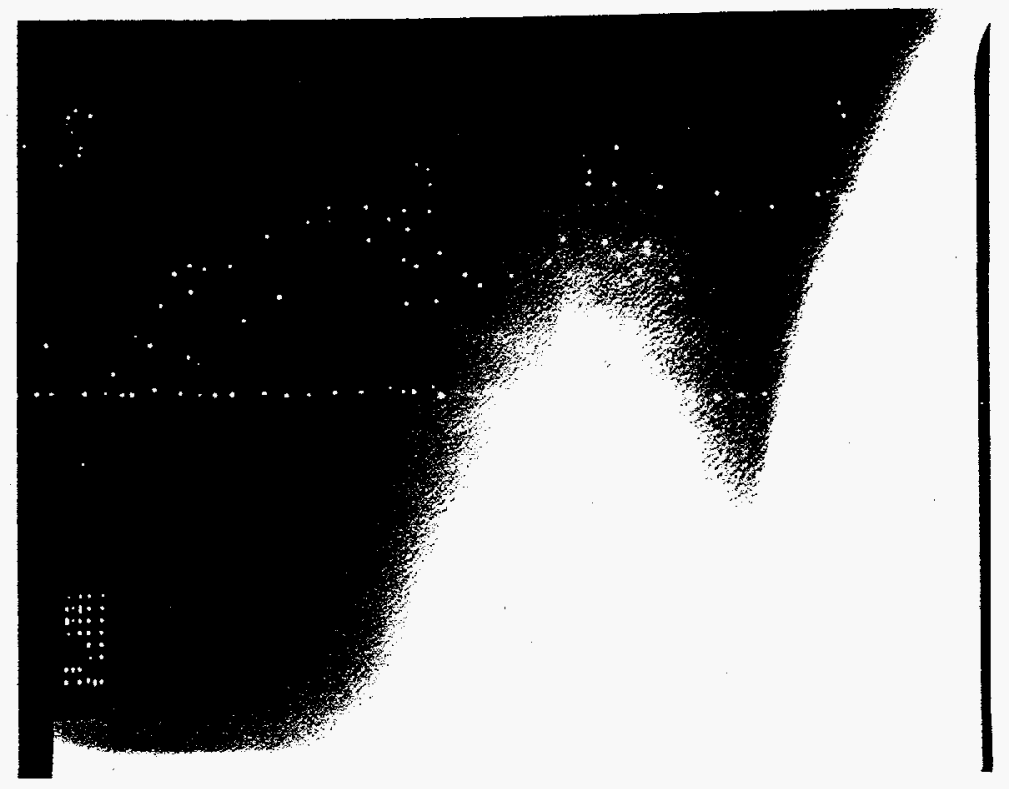

Figure 16. TEM Micrograph of the "As-Fabricated" WP202-15. (x100K)

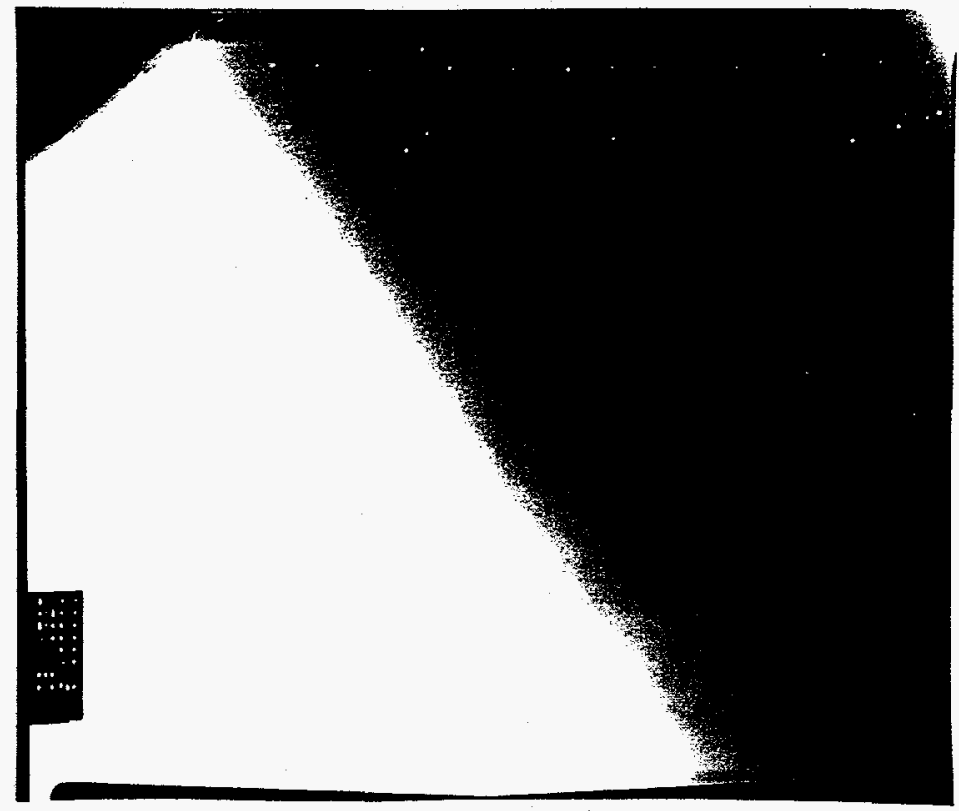

Figure 17. TEM Micrograph of the "As-Fabricated" WP202-15. (x100K) 


\section{Conclusions}

Based on the limited number of glasses evaluated in this study, the current phase separation discriminator predicts the development of amorphous phase separation with high confidence. Typically model predictions are conservative (due to large uncertainties) to ensure phase separated glasses are not produced which may unnecessarily limit the compositional operational window. Slight discrepancies between model predictions and microstructural analyses suggest that the immiscibility dome for these multicomponent glasses is in close proximity to predicted values but can be predictions could be enhanced.

Comparing relative durabilities to model predictions for phase separation, it appears that the development of amorphous phase separation translated into a reduction in durability for some of the simulated glasses. Although the durability was reduced, the boron release values were well below those of the Environmental Assessment glass. The reduction in durability suggests that a Type A or B microstructure developed in these glasses where the less durable phase was the continuous phase. However, it should be noted that durability reductions could also be the result of a lack of structural integrity (e.g., the effect of $\mathrm{Al}_{2} \mathrm{O}_{3}$ ) or the presence of crystalline phases. A more detailed evaluation of other WP200 and WP202 glasses is warranted to support this hypothesis.

If the position of the immiscibility dome is well understood, glasses can be formulated close to the immiscibility dome without risking the development of amorphous phase separation. This detailed understanding and the ability to predict the development of amorphous phase separation could translate into a larger compositional window from which the particular vitrification process is based.

\section{Path Forward}

The development of data, understanding, and quantitative description for composition and kinetic effects on the development of amorphous phase separation will continue in FY98 through the TFA. This effort will provide insight into the compositional effects on phase stability and will lead to a better understanding of the methods used to predict the development of amorphous phase separation in $\mathrm{HLW}$ glasses. The effect of $\mathrm{Al}_{2} \mathrm{O}_{3}$ and $\mathrm{P}_{2} \mathrm{O}_{5}$ will be the primary compositional effects evaluated. For example, various studies have indicated that the presence of $\mathrm{Al}_{2} \mathrm{O}_{3}$ in borosilicate glasses above a certain quantity (typically around $3.5-4 \mathrm{wt} \%$ ) will limit or suppress the development of amorphous phase separation. To address this issue, $\mathrm{HLW}$ glasses within the immiscibility dome will be evaluated with varied levels of $\mathrm{Al}_{2} \mathrm{O}_{3}$ and $\mathrm{P}_{2} \mathrm{O}_{5}$. The experiments will be coordinated with the joint PNNL-SRTC test matrix.

The experiments will be designed and performed to extend (where applicable) current models and better define their range of applicability. Generation of additional data (e.g., predicting the development of amorphous phase separation or nepheline precipitation) is expected to allow a larger processing window to be defined for DWPF or future HLW vitrification facilities at Hanford by relaxing model limitations. 


\section{Acknowledgments}

This work was prepared with the support of the following contributors:

Headquarters:

Office of Science and Technology

Dave W. Geiser, Program Manager

Focus Area/Programs:

Tanks Focus Area

Jeffrey A. Frey, Manager

Operations Office:

Richland Operations Office

Science and Technology Programs Division

Deborah E. Trader, Technical Program Officer

Contractor:

Pacific Northwest National Laboratory

Environmental Science and Technology

Environmental Technology Division

Rod K. Quinn, Manager

\section{References}

[1] M. Tomozawa, "Phase Separation in Glass", Treatise on Materials Science and Technology, Vol. 17, Glass II, M. Tomozawa and R.H. Doremus, editors, Academic Press, New York (1979).

[2] N.P. Danilova, O.V. Mazurin, and T.S. Tschomskaya, "The Influence of the Structure of Phase Separated Glasses on the Chemical Durability", Proceedings International Congress Glass $\left(9^{\text {th }}\right)$, Volume 9, Part 1, Institute dur Verre, Paris, pp. 825-842 (1971).

[3] P. Taylor, S.D. Ashmore, and D.G. Owen, "Chemical Durability of Some Sodium Borosilicate Glasses Improved by Phase Separation", Journal of the American Ceramic Society, Vol. 70, pp. 333 - 338 (1987).

[4] P. Taylor, A Review of Phase Separation in Borosilicate Glasses with Reference to Nuclear Fuel Waste Immobilization, AECL-10173, Whiteshell Nuclear Research Establishment, Pinawa, Manitoba, Canada (1990).

[5] Y. Kawamoto and M. Tomozawa, "Prediction of Immiscibility Boundaries of Ternary Silicate Glasses", Physics and Chemistry of Glasses, Vol. 22, pp. $11-16$ (1981).

[6] R.J. Charles "Metastable Immiscibility in the $\mathrm{BaO}-\mathrm{Li}_{2} \mathrm{O}-\mathrm{SiO}_{2}$ System", Physics and Chemistry of Glasses, Vol. 8, pp. 185-189 (1967). 
[7] E.M. Levin and S. Block, "Structural Interpretation of Immiscibility in Oxide Systems: I. Analysis and Calculation of Immiscibility", Journal of the American Ceramic Society, Vol. 40, pp. 95 - 106 (1957).

[8] Z. Strand and P. Strand, "Calculation of Metastable Two-Liquid Tie Lines in Ternary Glass-Forming Systems", Journal of the American Ceramic Society, Vol. 61, pp. 283-286 (1978).

[9] D.G. Burnett and R.W. Douglas, "Liquid-Liquid Phase Separation in the Soda-Lime-Silica System", Physics and Chemistry of Glasses, Vol. 11, pp. 125-135 (1970).

[10] P.R. Hrma, et. al., Property/Composition Relationships for Hanford HighLevel Waste Glasses Melting at $1150^{\circ} \mathrm{C}$, PNL-10359, Volumes 1 and 2 (1994).

[11] D.K. Peeler and P.R. Hrma, "Predicting Liquid Immiscibility in Multicomponent Nuclear Waste Glasses," Ceramic Transactions, Volume 45, pp. 219-229 (1994). 